\title{
COL6A1 knockdown suppresses cell proliferation and migration in human aortic vascular smooth muscle cells
}

\author{
ZONGXIANG CHEN*, QINGJIAN WU*, CHENGJUN YAN and JUAN DU \\ Emergency Department, Jining 1 People's Hospital, Jining, Shandong 272011, P.R. China
}

Received July 9, 2018; Accepted May 31, 2019

DOI: $10.3892 / \mathrm{etm} .2019 .7798$

\begin{abstract}
Vascular smooth muscle cell (VSMC) migration is an important pathophysiological signature of neointimal hyperplasia. The aim of the present study was to investigate the effects of collagen type VI $\alpha 1$ chain (COL6A1) on VSMC migration. COL6A1 expression was silenced in platelet-derived growth factor (PDGF-BB)-stimulated VSMCs. Cell counting kit-8, wound healing and Transwell assays were used to measure cell viability, migration and invasion, respectively. Reverse transcription-quantitative PCR and western blot analysis were performed to analyze the expression of factors associated with metastasis. COL6A1 silencing attenuated PDGF-BB-induced increases in cell viability and invasive abilities of VSMCs, in addition to partially reversing the increased expression of fibronectin (FN), matrix metalloproteinase (MMP)-2 and MMP-9 induced by PDGF-BB stimulation. The silencing of COL6A also overturned PDGF-BB-induced reduction in tissue inhibitor of metalloproteinase 2 expression in VSMCs. PDGF-BB activated the AKT/mTOR pathway, which was also inhibited by COL6A1 knockdown. Taken together, these findings suggest that COL6A1 silencing inhibited VSMC viability and migration by inhibiting AKT/mTOR activation.
\end{abstract}

\section{Introduction}

The incidence of cardiovascular diseases has been on the rise annually with the onset of aging. In particular, coronary heart disease is becoming increasingly common $(1,2)$. Although percutaneous coronary intervention (PCI) is a commonly used method to treat atherosclerotic coronary heart disease, postoperative restenosis occurs in a considerable proportion of angioplasty patients, leading to a reduction in the success

Correspondence to: Dr Juan Du, Emergency Department, Jining 1 People's Hospital, 6 Jiankang Road, Jining, Shandong 272011, P.R. China

E-mail: juand_duj@163.com

*Contributed equally

Key words: collagen type VI $\alpha 1$ chain, proliferation, migration, vascular smooth muscle cells rate of PCI treatment whilst increasing the risk of new cardiovascular complications (3). Indeed, restenosis is an important factor in the long-term outcome of post-angioplasty surgery (4), with the incidence of restenosis potentially reaching between 30 and 50\% within 6 months post-surgery without preventive measures (5). Despite developments in novel technology in combatting restenosis such as drug-eluting angioplasty balloons, the occurrence of restenosis remains high (6) due to the mechanism of restenosis being complex and not fully understood. Therefore, understanding the molecular mechanisms underlying vascular remodeling following injury is pivotal to the prevention of restenosis after PCI.

There is substantial evidence that aberrant proliferation of the vascular neointima is central to the pathophysiology of vascular lumen restenosis $(7,8)$; in which the phenotypic transformation of vascular smooth muscle cells (VSMCs) is the main cause. Following transformation, VSMCs display enhanced proliferative and migratory capabilities (9), but may exhibit different characteristics depending on the status of their microenvironment (10). In normal blood vessels, VSMCs are highly differentiated cells that exhibit a strong contractile phenotype, and serve to maintain and regulate vascular tone to stabilize blood pressure (11). However, under pathological conditions, including atherosclerosis and in-stent restenosis, VSMCs begin transforming into a more synthetic phenotype, characterized by high levels of proliferation and migration with a concomitant reduction in contractility $(12,13)$. This transition results in intima thickening of the arteries, which is a common pathogenesis in the formation of multiple vascular lesions in vivo (14). Therefore, understanding the changes in the proliferative and migratory capabilities of VSMCs has important implications for the prevention and treatment of these diseases.

Platelet-derived growth factors (PDGFs) are strong mitogens for VSMCs in blood vessels (15). PDGFs function in many vascular pathophysiological processes, such as atherosclerosis, restenosis and angiogenesis (16). PDGFs regulate cell proliferation, cell migration and the production of inflammatory mediators, to maintain tissue permeability and hemodynamics, through modulation of several transcription factors and key molecular signaling pathways (17). PDGF receptor signaling can activate cell proliferation and migration, protein production or secretion, and phenotypic modulation of VSMCs (18). Therefore, in the present study, PDGF-BB, the main isoform of PDGFs, was selected to induce VSMC dedifferentiation. 
Collagen type VI $\alpha 1$ chain (COL6A1) assists in the synthesis of collagen VI (COL6), which is a component of the extracellular matrix and forms distinct microfibrillar networks in the connective tissues of blood vessels and muscles $(19,20)$. High COL6A1 has been previously associated with hypertension, which is a main risk factor for cardiovascular diseases (21), whilst another study showed upregulated COL6A1 expression in the vascular tissues of patients with atherosclerosis (22). In addition, COL6A1 was identified as a metastasis-associated protein using quantitative secretome analysis (23) In light of these reports, it was therefore hypothesized that COL6A1 may serve important roles in the synthetic phenotype of VSMCs and the pathogenesis of vascular lumen restenosis. Therefore, in the present study, a COL6A1 silencing vector was constructed and transfected into aortic VSMCs to study the effects of COL6A1 on VSMC proliferation and invasion.

\section{Materials and methods}

Cell transfection. T/G Human aortic vascular smooth muscle cells (T/G HA-VSMC; HA-VSMC thereafter; cat. no. CL-0452; Procell Life Science \& Technology Co., Ltd.) were cultured in Medium 231 (Life Technologies; Thermo Fisher Scientific, Inc.) supplemented with 5\% smooth muscle growth supplement (SMGS; Thermo Fisher Scientific, Inc.) at $37^{\circ} \mathrm{C}$ under $5 \% \mathrm{CO}_{2}$. Fresh culture medium was changed every two days. HA-VSMCs ( $1 \times 10^{5}$ cells) were then transfected with $0.25 \mu \mathrm{g}$ siRNA specific for COL6A1 (si-COL6A1) or siRNA-control (EV; both purchased from Shanghai GenePharma Co., Ltd.) using Lipofectamine ${ }^{\circledR}$ 3000 (Invitrogen; Thermo Fisher Scientific, Inc.) according to manufacturer's protocol, the cells were named si-COL6A1 and EV cells thereafter. The sequences of si-COL6A1 were: Forward, 5'-CCCACCUGAAGGAGAAUAAUU-3' and reverse, 5'-UUA UUCUCCUUCAGGUGGGUU-3'. The sequences of EV were: Forward, 5'-UUCUCCGAACGUGUCACGUTT-3' and reverse, 5'-ACGUGACACGUUCGGAGAATT-3'. Cells without transfection were designated as the control group (Cntl). Transfection efficiency was determined by measuring COL6A1 mRNA and protein levels after $48 \mathrm{~h}$ of transfection.

Cell treatment. Each experiment was designed such that one group of cells received PDGF-BB and the other group did not. In PDGF-BB-treated groups, Cntl, EV and si-COL6A1 cells $\left(5 \times 10^{5}\right)$ were seeded into a six-well plate for $24 \mathrm{~h}$, then stimulated with $20 \mathrm{ng} / \mathrm{ml}$ platelet-derived growth factor (PDGF-BB; PeproTech, Inc.) diluted in Medium 231 supplemented 5\% SMGS for 12,24 and $48 \mathrm{~h}$ at $37^{\circ} \mathrm{C}$.

Cell viability assay. Cell viability was determined using Cell counting kit-8 (CCK-8; Dojindo Molecular Technologies, Inc.). Cntl, EV and si-COL6A1 cells were seeded into a 96-well plate at $5 \times 10^{3}$ cells/well and cultured for 12,24 or $48 \mathrm{~h}$ at $37^{\circ} \mathrm{C}$ with or without $20 \mathrm{ng} / \mathrm{ml}$ PDGF-BB. Following the addition of $20 \mu \mathrm{l} \mathrm{CCK}-8$ reagent/well and a further $1 \mathrm{~h}$ incubation, cell viability was measured by obtaining the optical density values at $450 \mathrm{~nm}$ for each well using a microplate reader (Thermo Fisher Scientific, Inc.).

Wound healing assay. HA-VSMC migration was measured using wound healing assay. Cntl, EV and si-COL6A1 cells treated or untreated with $20 \mathrm{ng} / \mathrm{ml}$ PDGF-BB were inoculated into a 12-well plate at $1 \times 10^{5}$ cells/well in Medium 231 supplemented with SMGS, and gently scratched to form a cell-free area. The cells were then incubated for $24 \mathrm{~h}$ at $37^{\circ} \mathrm{C}$. The width of each wound was measured using an Olympus DSX100 light microscope (Olympus Coporation; magnification, x200).

Cell invasion assay. The invasive abilities of HA-VSMCs were measured using 24-well Transwell ${ }^{\circledR}$ chambers with 8- $\mu \mathrm{m}$ pore filters (Corning Inc). Cntl, EV and si-COL6A1 cells $\left(5 \times 10^{4}\right.$ cells) treated or untreated with $20 \mathrm{ng} / \mathrm{ml}$ PDGF-BB, diluted in Medium 231 supplemented with SMGS, were seeded into the Matrigel $^{\circledR}$ GFR (BD Biosciences)-coated Transwell ${ }^{\circledR}$ upper chambers, with the coating process at $37^{\circ} \mathrm{C}$ for $30 \mathrm{~min}$. The lower chambers were filled with Medium 231 supplemented with SMGS. Following $24 \mathrm{~h}$ incubation, the Transwell membranes were stained using $0.1 \%$ crystal violet for $30 \mathrm{~min}$ at $37^{\circ} \mathrm{C}$. The number of invasive cells in random 5 fields was then calculated from images captured using Olympus DSX100 optical microscope (Olympus Corporation; magnification, x200).

Reverse transcription-quantitative PCR (RT-qPCR). Total RNA was extracted from Cntl, EV and si-COL6A1 cells $\left(5 \times 10^{5}\right.$ cells) treated or untreated with $20 \mathrm{ng} / \mathrm{ml}$ PDGF-BB using TRIzol (Invitrogen; Thermo Fisher Scientific, Inc.) according to manufacturer's protocol. cDNA was obtained using High-capacity cDNA Reverse Transcription kit (Applied Biosystems; Thermo Fisher Scientific, Inc.) according to manufacturer's protocol. The mRNA expression levels of factors associated with metastasis, including fibronectin (FN), matrix metalloproteinase (MMP)-2, MMP-9 and tissue inhibitor of metalloproteinases 2 (TIMP-2) were then measured using Fast SYBR ${ }^{\circledR}$ Green Master Mix (Applied Biosystems; Thermo Fisher Scientific, Inc.) according to manufacturer's protocol, in an Applied Biosystems 7300 thermocycler (Applied Biosystems; Thermo Fisher Scientific, Inc.). The following thermocycling conditions were used: Initial denaturation at $94^{\circ} \mathrm{C}$ for $25 \mathrm{sec} ; 35 \mathrm{cycles}$ of $94^{\circ} \mathrm{C}$ for $25 \mathrm{sec}, 60^{\circ} \mathrm{C}$ for $25 \mathrm{sec}$ and $72^{\circ} \mathrm{C}$ for $30 \mathrm{sec}$; and final extension at $72^{\circ} \mathrm{C}$ for $5 \mathrm{~min}$. The quantification was performed using the $2^{-\Delta \Delta \mathrm{Cq}}$ method (24). B-actin was used as internal control and the primer sequences were listed in Table I.

Western blot analysis. Cntl, EV and si-COL6A1 cells $\left(5 \times 10^{5}\right.$ cells) treated or untreated with $20 \mathrm{ng} / \mathrm{ml}$ PDGF-BB were lysed using RIPA lysis buffer (Boster Biological Technology) for $20 \mathrm{~min}$, with the proteins quantified using Bicinchoninic Acid protein assay kit (Pierce; Thermo Fisher Scientific, Inc.). All proteins were subsequently separated at $10 \mu \mathrm{g} /$ lane by $15 \%$ SDS-PAGE and transferred onto a PVDF membrane (Millipore; Merck KGaA). The membranes were blocked using 5\% non-fat dry milk in PBS, at $37^{\circ} \mathrm{C}$ for $1 \mathrm{~h}$, before being probed with primary antibodies specific for COL6A1 (cat. no. ab151422; 1:1,000), FN (cat. no. ab23750; 1:1,000), MMP-2 (cat. no. ab37150; 1:1,000), MMP-9 (cat. no. ab73734; 1:1,000), TIMP-2 (cat. no. ab180630; 1:1,000), protein kinase B (PKB/AKT; cat. no. ab8805; 1:500), phosphorylated (p)-AKT (p-AKT; cat. no. ab38449; 1:1,000), mammalian target of rapamycin (mTOR; cat. no. ab2732; 1:2,000), p-mTOR (p-mTOR; cat. no. ab84400; 1:500) and 
Table I. The primer sequences used for reverse transcription-quantitative PCR.

\begin{tabular}{|c|c|}
\hline Gene & Sequence $\left(5^{\prime}-3^{\prime}\right)$ \\
\hline \multirow[t]{2}{*}{$\beta$-actin } & Forward: GTGGACATCCGCAAAGAC \\
\hline & Reverse: GAAAGGGTGTAACGCAACT \\
\hline \multirow[t]{2}{*}{$\mathrm{FN}$} & Forward: ACAACACCGAGGTGACTGAGAC \\
\hline & Reverse: GGACACAACGATGCTTCCTGAG \\
\hline \multirow[t]{2}{*}{ MMP-2 } & Forward: CAGCCCTGCAAGTTTCCATT \\
\hline & Reverse: GTTGCCCAGGAAAGTGAAGG \\
\hline \multirow[t]{2}{*}{ MMP-9 } & Forward: GAGACTCTACACCCAGGACG \\
\hline & Reverse: GAAAGTGAAGGGGAAGACGC \\
\hline
\end{tabular}

FN, fibronectin; MMP, matrix metalloproteinase.

$\beta$-actin (cat. no. ab8227; $1: 2,000$ ) overnight at $4^{\circ} \mathrm{C} . \beta$-actin was used as loading control. Next, the membranes were incubated with horseradish peroxidase-conjugated secondary antibodies (ab6721, 1:5,000) for $2 \mathrm{~h}$ at $37^{\circ} \mathrm{C}$. All primary and secondary antibodies were purchased from Abcam. The protein bands were visualized using enhanced chemiluminescence reagents (Millipore; Merck KGaA) and quantified using Bio-Rad ChemiDoc $^{\text {TM }} \mathrm{XRS}^{+}$System with Image $\mathrm{Lab}^{\mathrm{TM}}$ software (version 4.1; Bio-Rad Laboratories, Inc.,).

Statistical analysis. SPSS 18.0 statistical software (SPSS, Inc.) was used for statistical analyzes. Five repeats were conducted for each experiment. Data were presented as the mean \pm standard deviation. One-way ANOVA was followed by Tukey's analysis for further comparison. $\mathrm{P}<0.05$ was considered to indicate a statistically significant difference.

\section{Results}

COL6A1 interference inhibits HA-VSMC viability following $P D G F-B B$ stimulation. HA-VSMCs were transfected with the si-COL6A1 recombinant plasmid before transfection efficiency was measured using RT-qPCR and western blotting. The mRNA and protein levels of COL6A1 were significantly downregulated in si-COL6A1 cells compared with those in the negative control EV group $(\mathrm{P}<0.01$; Fig. $1 \mathrm{~A}-\mathrm{C})$. HA-VSMCs in the Cntl, EV and si-COL6A1 groups were subsequently stimulated with PDGF-BB for 12, 24 and $48 \mathrm{~h}$, before cell viability was assessed using CCK-8 assay. PDGF-BB stimulation significantly increased HA-VSMC viability in the Cntl and EV groups after 24 and $48 \mathrm{~h}(\mathrm{P}<0.05$; Fig. 1D). There was no significant difference between the si-COL6A1 group in the absence of PDGF-BB and the si-COL6A1 group in the presence of PDGF-BB, at 24 and 48 h (Fig. 1D). No significant differences were observed in cell viability measured between Cntl, EV and si-COL6A1 groups after 12, 24 or $48 \mathrm{~h}$ in the absence of PDGF-BB treatment. These results demonstrate that PDGF-BB stimulation improved HA-VSMC viability, which can be negated by COL6A1 knockdown.

HA-VSMC migration is inhibited by COL6A1 interference following PDGF-BB stimulation. HA-VSMC migration was assessed using wound healing assay. PDGF-BB also appeared to have SIGNIFICANTLY increased HA-VSMC migration si-COL6A1 cell group, albeit not to the same magnitude as the other two conditions $(\mathrm{P}<0.01$; Fig. $2 \mathrm{~A}$ and $\mathrm{B})$. No significant differences were found between Cntl, EV and si-COL6A1 cell migration in the absence of PDGF-BB stimulation.

COL6A1 interference inhibits HA-VSMC invasion following $P D G F-B B$ stimulation. HA-VSMC invasion was measured using Matrigel-coated Transwell assays. PDGF-BB stimulation significantly increased the invasive capabilities of Cntl and EV cells, but the extent of increase in the si-COL6A1 cell group was significantly lower compared with the corresponding EV group $(\mathrm{P}<0.01$; Fig. $3 \mathrm{~A}$ and $\mathrm{B})$. In the absence of PDGF-BB, no significant differences were observed between the invasive abilities of Cntl, EV and si-COL6A1 cells.

COL6A1 regulates the expression of factors associated with migration/invasion in HA-VSMCs stimulated by PDGF-BB. RT-qPCR and western blot analysis were used to measure the expression levels of factors associated with migration/invasion in HA-VSMCs following PDGF-BB stimulation. PDGF-BB treatment significantly upregulated the expression levels of FN, MMP-2 and MMP-9 mRNA and protein in Cntl and EV cells, but the scale of this upregulation in si-COL6A1 cells was significantly lower compared with corresponding EV cells $(\mathrm{P}<0.05$; Fig. 4A-C and E-H). By contrast, PDGF-BB treatment significantly reduced TIMP-2 expression in Cntl and EV cells, but the extent of reduction was significantly smaller in si-COL6A1 cells compared with EV cells. $(\mathrm{P}<0.01$; Fig. 4 D, E and I).

COL6A1 interference inhibits the AKT-mTOR pathway in HA-VSMCs following PDGF-BB stimulation. AKT and mTOR phosphorylation in Cntl, EV and si-COL6A1 cells following PDGF-BB treatment were next measured using western blotting. p-AKT expression was reduced in the si-COL6A1 group in the absence of PDGF-BB, compared to the other two groups $(\mathrm{P}<0.05)$. Relative AKT and mTOR phosphorylation were significantly increased in Cntl and EV cells in response to PDGF-BB stimulation, but not in si-COL6A1 cells $(\mathrm{P}<0.01$; Fig. 5A-C).

\section{Discussion}

The phenotypic transformation of VSMCs serves an important pathophysiological role in neointimal hyperplasia after vascular injury and luminal stenosis, which is dependent upon conditions within its microenvironment $(25,26)$. PDGF-BB is an efficient mitogen stimulator of VSMCs that promote the dedifferentiation, proliferation and migration of VSMCs during vascular injury repair (27). Therefore, PDGF-BB was elected as the agonist in the present study to facilitate the phenotypic transformation of VSMCs. HA-VSMC viability, migratory and invasive capabilities were all found to be promoted by PDGF-BB stimulation.

COL6A1 is a protein associated with metastasis of cervical cancer (19) and, by influencing blood pressure, it is also a risk factor for cardiovascular diseases (28). In the present study, COL6A1 expression was knocked down in HA-VSMCs to study 
A

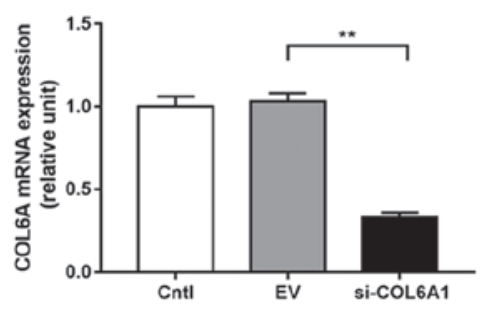

B

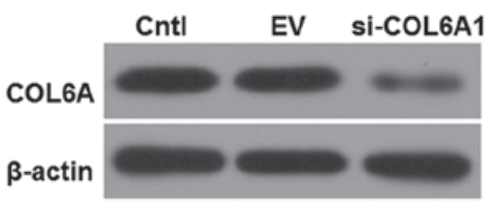

C

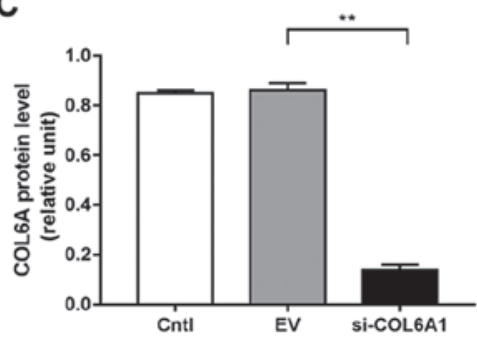

D

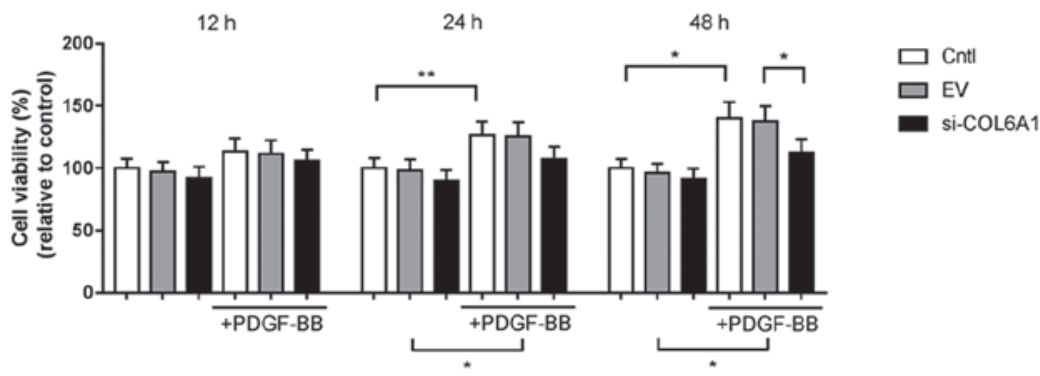

Figure 1. COL6A1 knockdown attenuated cell viability in PDGF-BB-stimulated HA-VSMCs. (A) Expression levels of COL6A1 mRNA were determined using reverse transcription-quantitative PCR following si-COL6A1 transfection. (B) COL6A1 protein levels were determined using western blotting after si-COL6A1 transfection. (C) Quantified densitometry results from the western blot analysis. (D) Cell viability after 12, 24 and 48 h were measured using Cell Counting Kit-8 assay after si-COL6A1 transfection and PDGF-BB stimulation. Each experiment was repeated five times. ${ }^{*} \mathrm{P}<0.05$ and ${ }^{* *} \mathrm{P}<0.01$. HA-VSMC, human aortic-vascular smooth muscle cells; COL6A1, collagen type VI $\alpha 1$ chain; PDGF-BB, platelet-derived growth factor; si, short interfering; Cntl, control; EV, siRNA-control.

A
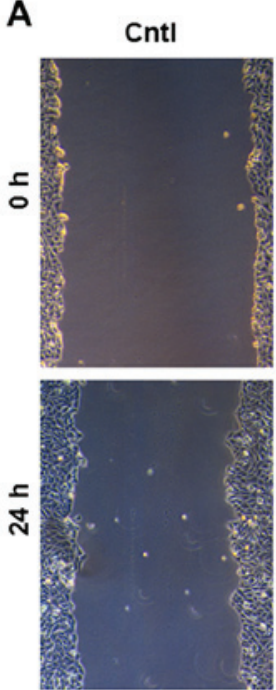

EV
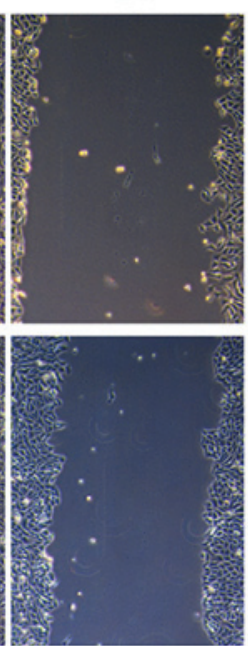

Si-COL6A1
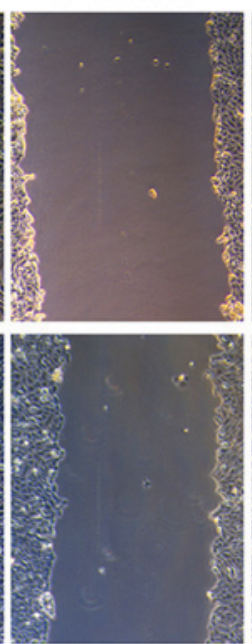

+PDGF-BB

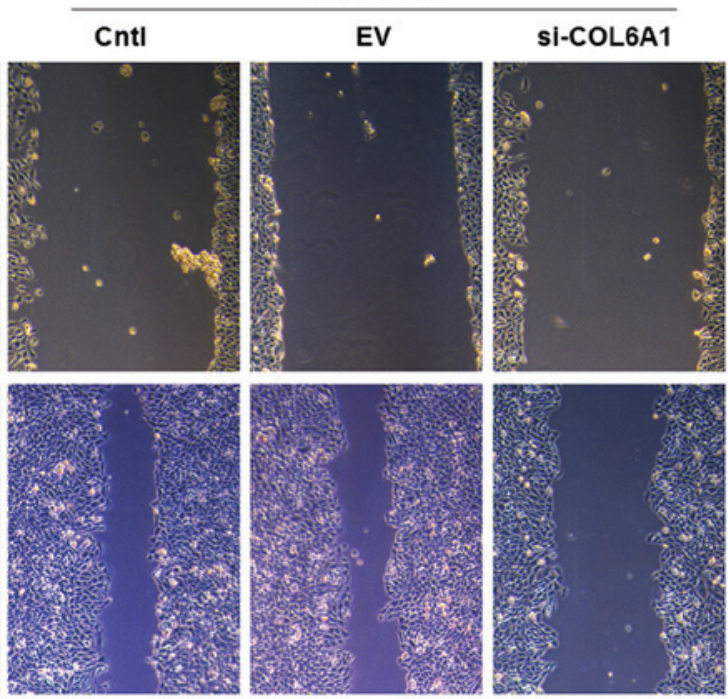

B

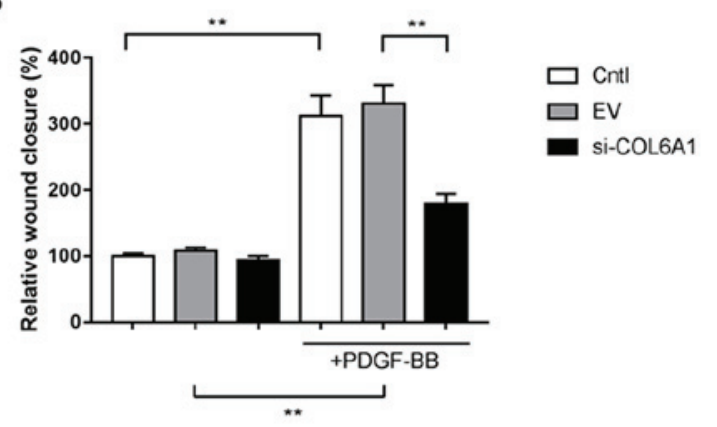

Figure 2. COL6A1 interference inhibited PDGF-BB-stimulated HA-VSMC migration. (A) Wound closure was measured in HA-VSMCs transfected with si-COL6A1 following PDGF-BB stimulation using wound healing assay. (B) Relative wound closure for each condition was quantified. Each experiment was repeated five times. ${ }^{* *} \mathrm{P}<0.01$. HA-VSMC, human aortic-vascular smooth muscle cells; COL6A1, collagen type VI $\alpha 1$ chain; PDGF-BB, platelet-derived growth factor; si, short interfering; Cntl, control; EV, siRNA-control. 

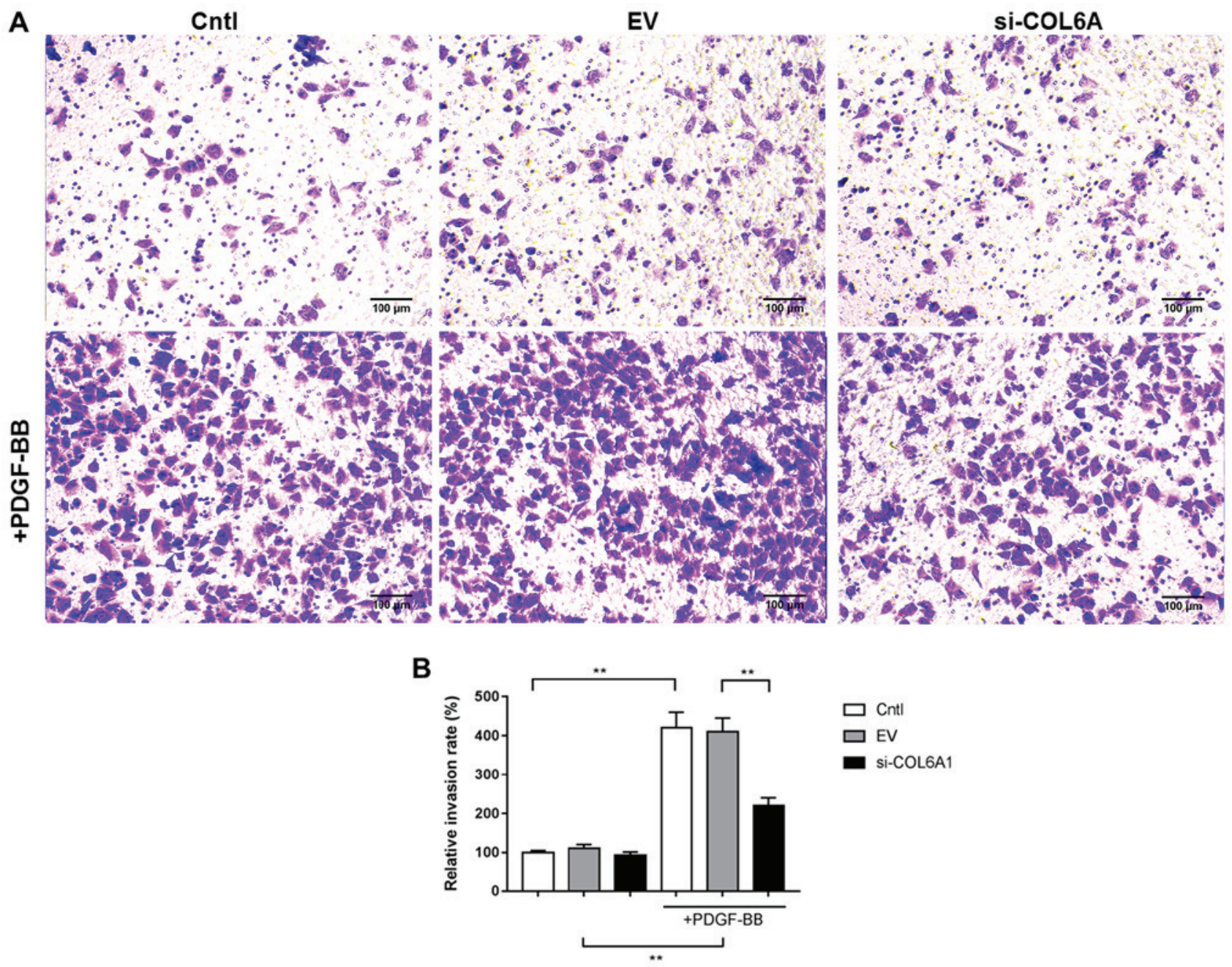

Figure 3. COL6A1 knockdown inhibited HA-VSMC invasion following PDGF-BB stimulation. (A) HA-VSMC invasion was measured using Matrigel-coated Transwell assay after si-COL6A1 transfection and PDGF-BB stimulation. (B) Relative invasion for each condition were quantified. Each experiment was repeated five times. ${ }^{* * *} \mathrm{P}<0.01$. HA-VSMC, human aortic-vascular smooth muscle cells; COL6A1, collagen type VI $\alpha 1$ chain; PDGF-BB, platelet-derived growth factor; si, short interfering; Cntl, control; EV, siRNA-control.

the function of COL6A1 on HA-VSMCs following PDGF-BB stimulation. It was found that cell viability, migratory and invasive abilities of VSMCs were all significantly potentiated by PDGF-BB treatment, which were partially negated by COL6A1 silencing. RT-qPCR and western blot analysis were subsequently performed to investigate the downstream effects of COL6A1 knockdown on PDGF-BB-stimulated VSMCs, specifically the expression of FN, MMP-2, MMP-9 and TIMP-2, classical factors associated with migration and invasion (29). PDGF-BB promoted FN, MMP-2 and MMP-9 expression whilst downregulating TIMP-2 expression; all of which were partially reversed by COL6A1 knockdown.

$\mathrm{FN}$ is an important component of the extracellular matrix which is upregulated in renal cell carcinoma cells (30). Non-enzymatic glycation interferes with FN-integrin interactions in VSMC and glycation of FN shifts the nature of cellular adhesion from integrin- to receptor for advanced glycation end products-dependent mechanisms (31). MMPs are proteolytic enzymes that require calcium, zinc and other metal ions as cofactors $(32,33)$. MMP-9 was reported to be associated with cell proliferation and migration of VSMCs (34). In particular, MMP-2 and MMP-9 serve important roles in the proliferation and migration of VSMCs (35). During VSMC proliferation and migration, the outer membrane of VSMCs interacts with the extracellular matrix to release MMPs for subsequent degradation (36). In contrast, TIMP-2 is a key inhibitor of MMPs and suppresses cell migration/invasion by inhibiting the function of MMPs (37). In the present study, the reduction in FN, MMP-2 and MMP-9 expression, in conjunction with the increase in TIMP-2 expression were caused by COL6A1 knockdown in VSMCs.

The PI3K/AKT signaling pathway commonly serves roles in a number of physiological processes, including cell proliferation, migration, invasion and angiogenesis $(38,39)$. Importantly, it is also the central signaling component of PDGF-BB induced invasion in VSMCs. PDGF-BB-induced cell growth and migration of human airway smooth muscle (40), retinal pigment epithelial (41) and endothelial progenitor cells (42) were all closely associated with the PI3K/AKT pathway. The activation of mTOR has also been reported in the PDGF-BB-induced proliferation and migration of VSMCs (43-45). In the present study, the phosphorylation levels of AKT and mTOR were significantly increased by PDGF-BB treatment in VSMCs, consistent with data from the 
A

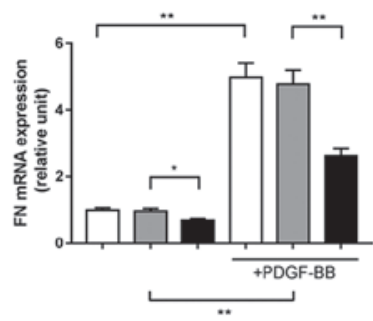

E
B

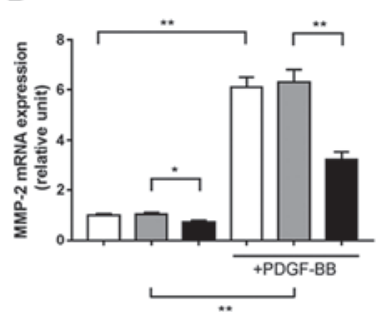

c

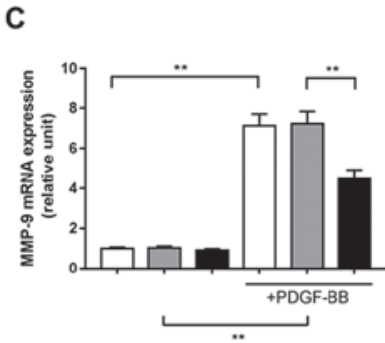

$\mathbf{F}$

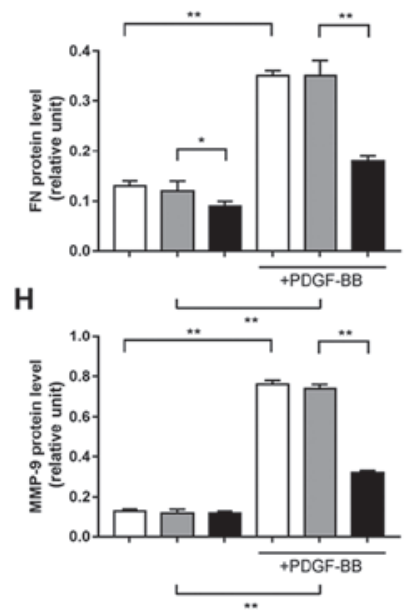

H

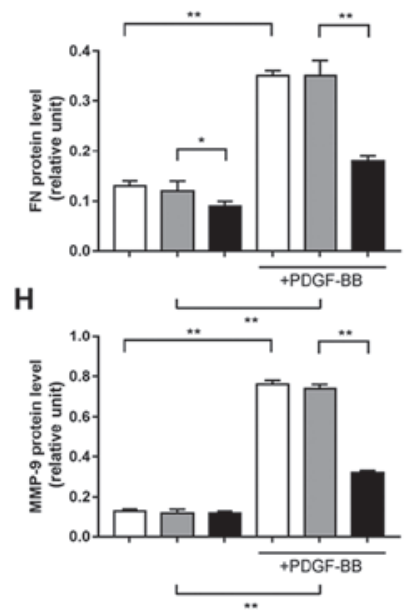

D

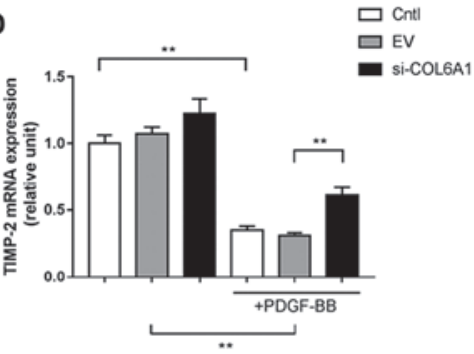

G
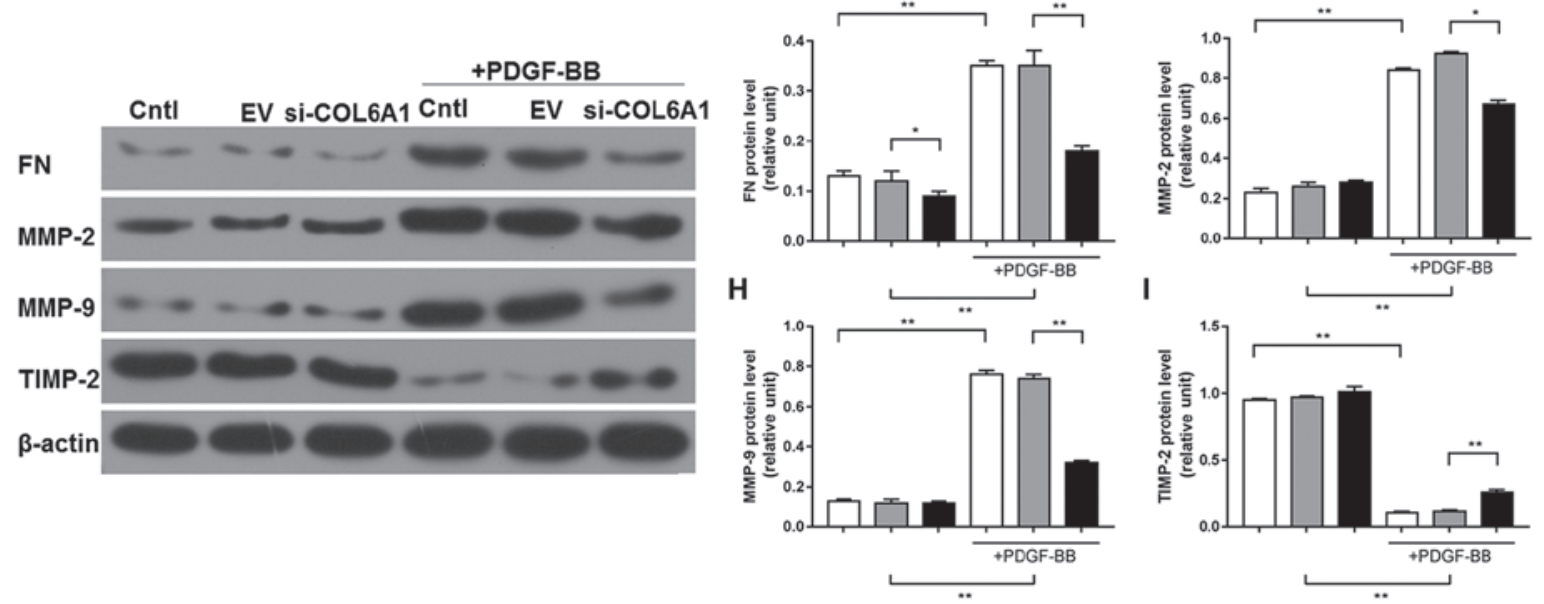

Figure 4. COL6A1 regulate the expression of factors associated with migration and invasion in HA-VSMCs following PDGF-BB stimulation. (A) Reverse transcription-quantitative PCR was performed to determine the levels of mRNA expression of FN, (B) MMP-2, (C) MMP-9 and (D) TIMP-2 after si-COL6A1 transfection and PDGF-BB stimulation. (E-I) Western blot analysis was performed to determine the protein expression levels of (F) FN, (G) MMP-2, (H) MMP-9 and (I) TIMP-2 after si-COL6A1 transfection and PDGF-BB stimulation. Each experiment was repeated five times. ${ }^{*} \mathrm{P}<0.05$, and ${ }^{* *} \mathrm{P}<0.01$. HA-VSMC, human aortic-vascular smooth muscle cells; COL6A1, collagen type VI $\alpha 1$ chain; PDGF-BB, platelet-derived growth factor; FN, fibronectin; MMP, matrix metalloproteinase; TIMP-2, tissue inhibitor of metalloproteinase-2; si, short interfering; Cntl, control; EV, siRNA-control.

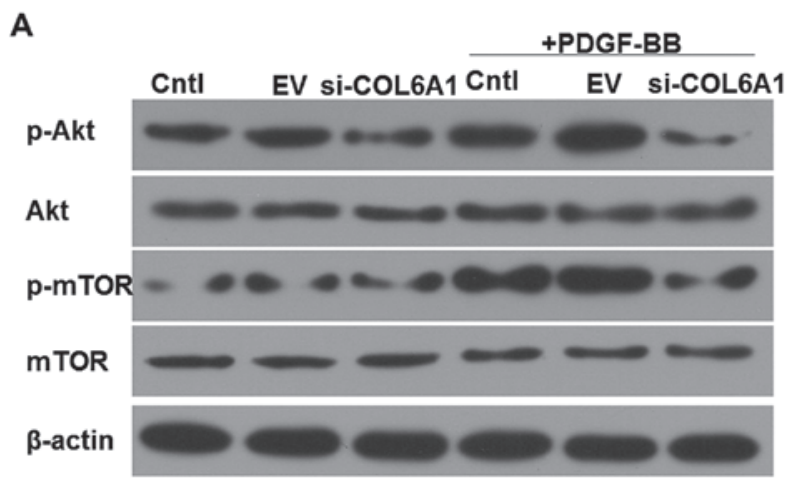

B

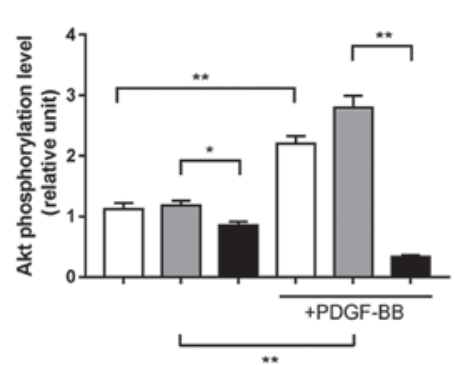

C

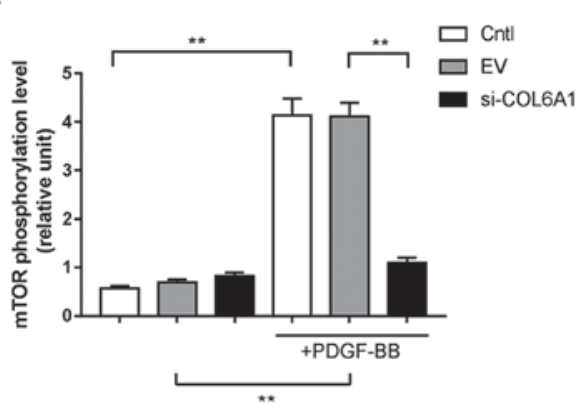

Figure 5. AKT-mTOR pathway was inhibited by COL6A1 knockdown in HA-VSMCs following PDGF-BB stimulation. (A-C) The levels of phosphorylation relative to the total expression of their respective proteins of (B) AKT and (C) mTOR in HA-VSMCs were analyzed and quantified using western blot analysis following si-COL6A1 transfection and PDGF-BB stimulation. Each experiment was repeated five times. ${ }^{*} \mathrm{P}<0.05$ and ${ }^{* * *} \mathrm{P}<0.01$. HA-VSMC, human aortic-vascular smooth muscle cells; COL6A1, collagen type VI $\alpha 1$ chain; PDGF-BB, platelet-derived growth factor; si, short interfering; Cntl, control; EV, siRNA-control. 
previous studies aforementioned. The silencing of COL6A1 potently reversed PDGF-BB-induced activation of AKT and mTOR in VSMCs. These observations suggest that COL6A1 knockdown inhibited VSMC viability, migration and invasion by suppressing Akt/mTOR activation.

In conclusion, the silencing of COL6A1 inhibited cell viability, migration and invasion of PDGF-BB-stimulated VSMCs by suppressing the expression of MMPs and Akt/mTOR activation. This suggest that COL6A1 may be a potential therapeutic target in the treatment of cardiovascular diseases, but this needs to be investigated further.

\section{Acknowledgements}

Not applicable.

\section{Funding}

No funding was received.

\section{Availability of data and materials}

The analyzed data sets generated during the study are available from the corresponding author upon reasonable request.

\section{Authors' contributions}

ZC and QW performed PCR and western blotting assays. CY performed the remaining assays. JD conceived and designed the study.

\section{Ethics approval and consent to participate}

Not applicable.

\section{Patient consent for publication}

Not applicable.

\section{Competing interests}

The authors declare that they have no competing interests.

\section{References}

1. Tian Y, Deng P, Li B, Wang J, Li J, Huang Y and Zheng Y: Treatment models of cardiac rehabilitation in patients with coronary heart disease and related factors affecting patient compliance. Rev Cardiovasc Med 20: 27-33, 2019.

2. Khamis RY, Ammari T and Mikhail GW: Gender differences in coronary heart disease. Heart 102: 1142-1149, 2016.

3. Orme RC, Parker WAE, Thomas MR, Judge HM, Baster K, Sumaya W, Morgan KP, McMellon HC, Richardson JD, Grech ED, et al: Study of two dose regimens of ticagrelor compared with clopidogrel in patients undergoing percutaneous coronary intervention for stable coronary artery disease (STEEL-PCI). Circulation: Jun 21, 2018 (Epub ahead of print) doi: 10.1161/CIRCULATIONAHA.118.034790.

4. Lee MS, Cheng RK, Kandzari DE and Kirtane AJ: Long-term outcomes of heart transplantation recipients with transplant coronary artery disease who develop in-stent restenosis after percutaneous coronary intervention. Am J Cardiol 109: 1729-1732, 2012.

5. Prasad K: Do statins have a role in reduction/prevention of post-PCI restenosis? Cardiovasc Ther 31: 12-26, 2013.
6. Fang CY, Fang HY, Chen CJ, Yang CH, Wu CJ and Lee WC: Comparison of clinical outcomes after drug-eluting balloon and drug-eluting stent use for in-stent restenosis related acute myocardial infarction: A retrospective study. PeerJ 6: e4646, 2018.

7. Lee KJ, Park SH, Lee JY, Joo HC, Jang EH, Youn YN and Ryu W: Perivascular biodegradable microneedle cuff for reduction of neointima formation after vascular injury. J Control Release 192: 174-181, 2014.

8. Ishimura S, Furuhashi M, Mita T, Fuseya T, Watanabe Y, Hoshina K, Kokubu N, Inoue K, Yoshida H and Miura T: Reduction of endoplasmic reticulum stress inhibits neointima formation after vascular injury. Sci Rep 4: 6943, 2014.

9. Guan H, Gao L, Zhu L, Yan L, Fu M, Chen C, Dong X, Wang L, Huang $\mathrm{K}$ and Jiang $\mathrm{H}$ : Apigenin attenuates neointima formation via suppression of vascular smooth muscle cell phenotypic transformation. J Cell Biochem 113: 1198-1207, 2012.

10. Zhang J, Chen J, Xu C, Yang J, Guo Q, Hu Q and Jiang H: Resveratrol inhibits phenotypic switching of neointimal vascular smooth muscle cells after balloon injury through blockade of Notch pathway. J Cardiovasc Pharmacol 63: 233-239, 2014.

11. Tang L, Dai F, Liu Y, Yu X, Huang C, Wang Y and Yao W: RhoA/ROCK signaling regulates smooth muscle phenotypic modulation and vascular remodeling via the JNK pathway and vimentin cytoskeleton. Pharmacol Res 133: 201-212, 2018.

12. Yang F, Chen Q, He S, Yang M, Maguire EM, An W, Afzal TA, Luong LA, Zhang L and Xiao Q: miR-22 is a novel mediator of vascular smooth muscle cell phenotypic modulation and neointima formation. Circulation 137: 1824-1841, 2018.

13. Hasanov Z, Ruckdeschel T, König C, Mogler C, Kapel SS, Korn C, Spegg C, Eichwald V, Wieland M, Appak S and Augustin HG: Endosialin promotes atherosclerosis through phenotypic remodeling of vascular smooth muscle cells. Arterioscler Thromb Vasc Biol 37: 495-505, 2017.

14. Shi N, Li CX, Cui XB, Tomarev SI and Chen SY: Olfactomedin 2 regulates smooth muscle phenotypic modulation and vascular remodeling through mediating runt-related transcription factor 2 binding to serum response factor. Arterioscler Thromb Vasc Biol 37: 446-454, 2017.

15. Wang JC, Li GY, Wang B, Han SX, Sun X, Jiang YN, Shen YW, Zhou C, Feng J, Lu SY, et al: Metformin inhibits metastatic breast cancer progression and improves chemosensitivity by inducing vessel normalization via PDGF-B downregulation. J Exp Clin Cancer Res 38: 235, 2019.

16. Hellström M, Kalén M, Lindahl P, Abramsson A and Betsholtz C: Role of PDGF-B and PDGFR-beta in recruitment of vascular smooth muscle cells and pericytes during embryonic blood vessel formation in the mouse. Development 126: 3047-3055, 1999.

17. Zhan Y, Kim S, Izumi Y, Izumiya Y, Nakao T, Miyazaki H and Iwao H: Role of JNK, p38, and ERK in platelet-derived growth factor-induced vascular proliferation, migration, and gene expression. Arterioscler Thromb Vasc Biol 23: 795-801, 2003.

18. Satoh K, Kikuchi N, Kurosawa R and Shimokawa H: PDE1C negatively regulates growth factor receptor degradation and promotes VSMC proliferation. Circ Res 116: 1098-1100, 2015.

19. Hou T, Tong C, Kazobinka G, Zhang W, Huang X, Huang Y and Zhang Y: Expression of COL6A1 predicts prognosis in cervical cancer patients. Am J Transl Res 8: 2838-2844, 2016.

20. Wan F, Wang H, Shen Y, Zhang H, Shi G, Zhu Y, Dai B and Ye D: Upregulation of COL6A1 is predictive of poor prognosis in clear cell renal cell carcinoma patients. Oncotarget 6: 27378-27387, 2015.

21. Nandakumar P, Lee D, Richard MA, Tekola-Ayele F, Tayo BO, Ware E, Sung YJ, Salako B, Ogunniyi A, Gu CC, et al: Rare coding variants associated with blood pressure variation in 15 914 individuals of African ancestry. J Hypertens 35: 1381-1389, 2017.

22. Sleptsov AA, Nazarenko MS, Lebedev IN, Skriabin NA, Frolov AV, Popov VA, Barbarash LS and Puzyrev VP: Somatic genome variations in vascular tissues and peripheral blood leukocytes in patients with atherosclerosis. Genetika 50: 986-995, 2014 (In Russian).

23. Chiu KH, Chang YH, Wu YS, Lee SH and Liao PC: Quantitative secretome analysis reveals that COL6A1 is a metastasis-associated protein using stacking gel-aided purification combined with iTRAQ labeling. J Proteome Res 10: 1110-1125, 2011.

24. Livak KJ and Schmittgen TD: Analysis of relative gene expression data using real-time quantitative PCR and the 2(-Delta Delta C(T)) method. Methods 25: 402-408, 2001. 
25. Zhang MJ, Zhou Y, Chen L, Wang YQ, Wang X, Pi Y, Gao CY, Li JC and Zhang LL: An overview of potential molecular mechanisms involved in VSMC phenotypic modulation. Histochem Cell Biol 145: 119-130, 2016.

26. Fellows BD, Ghobrial N, Mappus E, Hargett A, Bolding M, Dean D and Mefford OT: In vitro studies of heparin-coated magnetic nanoparticles for use in the treatment of neointimal hyperplasia. Nanomedicine 14: 1191-1200, 2018.

27. Chen S, Liu B, Kong D, Li S, Li C, Wang H and Sun Y: Atorvastatin calcium inhibits phenotypic modulation of PDGF-BB-induced VSMCs via down-regulation the Akt signaling pathway. PLoS One 10: e0122577, 2015.

28. Sato T, Takano R, Tokunaka K, Saiga K, Tomura A, Sugihara H, Hayashi T, Imamura Y and Morita M: Type VI collagen $\alpha 1$ chain polypeptide in non-triple helical form is an alternative gene product of COL6A1. J Biochem 164: 173-181, 2018.

29. Prado AF, Pernomian L, Azevedo A, Costa RAP, Rizzi E, Ramos J, Paes Leme AF, Bendhack LM, Tanus-Santos JE and Gerlach RF: Matrix metalloproteinase-2-induced epidermal growth factor receptor transactivation impairs redox balance in vascular smooth muscle cells and facilitates vascular contraction. Redox Biol 18: 181-190, 2018.

30. Ou YC, Li JR, Wang JD, Chang CY, Wu CC, Chen WY, Kuan YH, Liao SL, Lu HC and Chen CJ: Fibronectin promotes cell growth and migration in human renal cell carcinoma cells. Int J Mol Sci 20: E2792, 2019.

31. Dhar S, Sun Z, Meininger GA and Hill MA: Nonenzymatic glycation interferes with fibronectin-integrin interactions in vascular smooth muscle cells. Microcirculation 24: 2017 doi: $10.1111 /$ micc. 12347.

32. Hunter MC, O'Hagan KL, Kenyon A, Dhanani KC, Prinsloo E and Edkins AL: Hsp90 binds directly to fibronectin (FN) and inhibition reduces the extracellular fibronectin matrix in breast cancer cells. PLoS One 9: e86842, 2014.

33. Yang M, Fan Z, Wang F, Tian ZH, Ma B, Dong B, Li Z, Zhang M and Zhao W: BMP-2 enhances the migration and proliferation of hypoxia-induced VSMCs via actin cytoskeleton, CD44 and matrix metalloproteinase linkage. Exp Cell Res 368: 248-257, 2018.

34. Yin J, Xia W, Wu M, Zhang Y, Huang S, Zhang A and Jia Z: Inhibition of mitochondrial complex I activity attenuates neointimal hyperplasia by inhibiting smooth muscle cell proliferation and migration. Chem Biol Interact 304: 73-82, 2019.

35. Song IS, Jeong YJ, Park JH, Shim S and Jang SW: Chebulinic acid inhibits smooth muscle cell migration by suppressing PDGF-R $\beta$ phosphorylation and inhibiting matrix metalloproteinase-2 expression. Sci Rep 7: 11797, 2017.
36. Seo KW, Lee SJ, Ye BH, Kim YW, Bae SS and Kim CD Mechanical stretch enhances the expression and activity of osteopontin and MMP-2 via the Akt1/AP-1 pathways in VSMC. J Mol Cell Cardiol 85: 13-24, 2015.

37. Smiljanic K, Obradovic M,Jovanovic A,Djordjevic J, Dobutovic B, Jevremovic D, Marche P and Isenovic ER: Thrombin stimulates VSMC proliferation through an EGFR-dependent pathway: Involvement of MMP-2. Mol Cell Biochem 396: 147-160, 2014.

38. Hu Q, Lin X, Ding L, Zeng Y, Pang D, Ouyang N, Xiang Y and Yao H: ARHGAP42 promotes cell migration and invasion involving PI3K/Akt signaling pathway in nasopharyngeal carcinoma. Cancer Med 7: 3862-3874, 2018.

39. Han R, Gu S, Zhang Y, Luo A, Jing X, Zhao L, Zhao X and Zhang L: Estrogen promotes progression of hormone-dependent breast cancer through CCL2-CCR 2 axis by upregulation of Twist via PI3K/AKT/NF-kappaB signaling. Sci Rep 8: 9575, 2018.

40. Zhou H, Wu Q, Wei L and Peng S: Paeoniflorin inhibits PDGFBBinduced human airway smooth muscle cell growth and migration. Mol Med Rep 17: 2660-2664, 2018.

41. Chan CM, Chang HH, Wang VC, Huang CL and Hung CF: Inhibitory effects of resveratrol on PDGF-BB-induced retinal pigment epithelial cell migration via PDGFR $\beta$, PI3K/Akt and MAPK pathways. PLoS One 8: e56819, 2013

42. Wang H, Yin Y, Li W, Zhao X, Yu Y, Zhu J, Qin Z, Wang Q, Wang K, Lu W, et al: Over-expression of PDGFR- $\beta$ promotes PDGF-induced proliferation, migration, and angiogenesis of EPCs through PI3K/Akt signaling pathway. PLoS One 7: e30503, 2012.

43. Cidad P, Miguel-Velado E, Ruiz-McDavitt C, Alonso E, Jiménez-Pérez L, Asuaje A, Carmona Y, García-Arribas D, López J, Marroquín Y, et al: Kv1.3 channels modulate human vascular smooth muscle cells proliferation independently of mTOR signaling pathway. Pflugers Arch 467: 1711-1722, 2015.

44. Lu QB, Wan MY, Wang PY, Zhang CX, Xu DY, Liao X and Sun HJ: Chicoric acid prevents PDGF-BB-induced VSMC dedifferentiation, proliferation and migration by suppressing ROS/NFKB/mTOR/ P70S6K signaling cascade. Redox Biol 14: 656-668, 2018.

45. Pan S, Lin H, Luo H, Gao F, Meng L, Zhou C, Jiang C, Guo Y, Ji Z, Chi J and Guo H: Folic acid inhibits dedifferentiation of PDGF-BB-induced vascular smooth muscle cells by suppressing mTOR/P70S6K signaling. Am J Transl Res 9: 1307-1316, 2017.

This work is licensed under a Creative Commons

Attribution-NonCommercial-NoDerivatives 4.0

International (CC BY-NC-ND 4.0) License. 